\title{
On some problems of the mechanical theory of heat
}

\section{Professor Ludwig Boltzmann}

To cite this article: Professor Ludwig Boltzmann (1878) On some problems of the mechanical theory of heat, Philosophical Magazine Series 5, 6:36, 236-237, DOI: 10.1080/14786447808639502

To link to this article: http://dx.doi.org/10.1080/14786447808639502

曲 Published online: 13 May 2009.

Submit your article to this journal $\sqsubset \pi$

Џ Article views: 21

Q View related articles $\square$

Citing articles: 1 View citing articles 5 


\section{[ 236 ] \\ XXXI. Intelligence and Miscellaneous Articles.}

\section{ON SOME PROBLEMS OF THE MECHANICAL THEORY OF HEAT.} BY PROFESSOR LUDWIG BOLTZMANN.

THE first section of the memoir has for its subject the relation between the Second Proposition and the calculation of probabilities; the second, the thermal equilibrium of a heavy gas. To these the author adds the following communication:- In the Beiblätter to Wiedemann's Annalen der Physik, Band II. Stück 5, is a treatise by S. Tolver Preston, in which the diffusion of gases is brought into relation with the Second Proposition of the mechanical theory of heat. This cannot (as, according to the notice in the Beiblätter, the author seems to think) serve for the refutation of that proposition; but it may well be a new and interesting application of it. There is in the same Stück of the Beiblätter a notice of a memoir by M. Clausius on this subject. Now, knowing nothing more of the contents of the memoir than what may be gathered from this notice, and not in the least wishing to forestall it, I will merely mention that, as it appears to me, the most essential problem that here comes into question, namely the calculation of how much heat can be transformed into work without any other compensation than the mixture of two dissimilar gases-or, to ase the terminology of M. Clausius, the calculation of the transformation-value of the mixture of two dissimilar gases-is only a special case of some calculations which I have carried out in my treatise "On the Relation between the Second Proposition of the Mechanical Theory of Heat and the Calculation of Probabilities as regards the Propositions respecting Thermal Equilibrium." I have, namely, there considered quite generally the case that in any mixture of substances, whether it be the mixture or the distribution of velocities or of directions of velocities, the entropy does not perfectly correspond to the definitive final state, and have shown that then it must always be less than in the definitive final state, so that consequently, on the transition into the latter, heat may be converted into work; and I have given a formula (formula 51) by which the difference of entropy, and consequently also the amount of the convertible heat, can be calculated.

From this formula (51) it immediately follows that the entropy of a mixture of several gases is exactly equal to the sum of the entropies which would belong to the individual gases if, at the same temperature and under the same partial pressure, each were alone present in space. If $V$ is the volume, $T$ the absolute temperature, $k$ the weight of the gas, $c$ and $c^{\prime}$ its two specific heats, then its entropy (by which $\mathrm{I}$ understand $\int \frac{d \mathrm{Q}}{\mathrm{T}}, d \mathrm{Q}$ being $=$ the heat introduced) is

$$
k \int \frac{c d \mathrm{~T}}{\mathrm{~T}}+k\left(c^{t}-c\right) \log \mathrm{V} .
$$

We will now consider two cases: first, two different gases are present in two different spaces $V_{1}$ and $V_{2}$, under equal pressure $p$ 
and at the same temperature $T$; secondly, the same gases are mixed, at the same temperature, in the space $V_{1}+V_{2}$, while the total pressure is equal to the previous pressure of each separate gas. In the first case let $\mathrm{E}_{1}$ be the entropy of the first, $\mathrm{E}_{2}$ that of the second gas ; in the second case let $\mathrm{E}_{12}$ be that of the mixture. According to the rule given above, $\mathbf{E}_{1}, \mathbf{E}_{2}$, and $\mathrm{E}_{12}$ can be calculated by means of the above formula. We thus find

$\mathrm{T}\left(\mathrm{E}_{12}-\mathrm{E}_{1}-\mathrm{E}_{2}\right)=\mathrm{T}\left(\gamma^{\prime}-\gamma\right)\left[\left(\mathrm{V}_{1}+\mathrm{V}_{2}\right) l\left(V_{1}+\mathrm{V}_{2}\right)-\mathrm{V}_{1} l \mathrm{~V}_{1}-\mathrm{V}_{2} l \mathrm{~V}_{2}\right]$.

But this is the expression for the quantity of heat which can be converted into work without any other compensation than the mix ture of the two gases. Therein is $\gamma^{\prime}-\gamma$ the product of the weight of unit volume into the difference of the two specific heats, which product has the same value for both gases.

The total work which can be gained from this heat is, according to known principles,

$$
p\left[\left(\mathrm{~V}_{1}+\nabla_{2}\right) l\left(\mathrm{~V}_{1}+\mathrm{V}_{2}\right)-\mathrm{V}_{1} l \mathrm{~V}_{1}-\mathrm{V}_{2} l \mathrm{~V}_{2}\right]
$$

To gain this total work, of course we should not have recourse to the expedient of diffusion through porous partitions, but convey the one gas into the other by means of a substance that chemically combines with one of the gases under partial dissociation (as quick-lime with carbonic acid), of course taking care that the process always remains reversible. We should, for example, first indefinitely expand the first gas, then with the substance above mentioned transfer it very slowly into the other, while, again, it would be continually compressed so that the partial pressure of the first gas was always equal in both vessels. Lastly, the mixture of gases must be so far expanded that its volume shall be equal to the sum of the volumes of the original gases. Since all these processes can easily be accompanied by calculation, it will be easy in this way to verify the above-given formula.-Kaiserliche Akademie der Wissenschaften in Wien, mathematisch-naturwissenschaftliche Classe, June 6, 1878.

ON THE RELATION OF THE WORK PERFORMED BY DIFFUSION TO

THE SECOND PROPOSITION OF THE MECHANICAL THEORY OF

HEAT. BY PROF. R. ClaUSIUS.

In 'Nature' for January 1878 (vol. xvii. p. 202), Mr. Tolver Preston has specified a process by means of which mechanical work can be gained through diffusion of gases. The reflections he makes upon this fact are very ingenious, and in relation to theory very interesting on account of the conclusions to which they give occasion; only in one point I think I must express a view different from his: he thinks, namely, that the result of his process contradicts the second proposition of the mechanical theory of heat; and in this $I$ cannot coincide.

The substance of his process is as follows. He imagines a cylinder divided into two sections by a movable piston. The piston consists of a porous substance, such as pipe-clay or graphite. In the two divisions of the cylinder two different gases are present, oxygen and hydrogen for instance. 